\title{
OPTIMIZATION OF DISPATCHING CRITERIA FOR OPEN-PIT TRUCK HAULAGE SYSTEM DESIGN USING MULTIPLE COMPARISONS WITH THE BEST AND COMMON RANDOM NUMBERS
}

\author{
Bozo Kolonja \\ University of Belgrade \\ Belgrade, Yugoslavia
}

\author{
David R. Kalasky \\ Systems Modeling Corporation \\ Sewickley, PA
}

\author{
Jan M. Mutmansky \\ The Pennsylvania State University \\ University Park, PA
}

\begin{abstract}
This paper considers simulation of truck dispatching system designs using maximum expected production of the truck-shovel system as the measure of performance. Two methods are utilized, multiple comparisons with the best (MCB) and the combination of $\mathrm{MCB}$ and the variance reduction technique known as common random numbers (CRN). These two techniques are compared via simulation experiments. The results show that the combined procedure of $\mathrm{MCB}$ with $\mathrm{CRN}$ is the superior tool to reduce the total number of replications needed to ensure the specified probability of correct selection over the finite number of designing systems. In this case study, MCB with CRN reduces the variance by $29 \%$ and the number of required replications by $48 \%$. Also, the $\mathrm{MCB}$ with $\mathrm{CRN}$ procedure narrowed the confidence interval by $18 \%$.
\end{abstract}

\section{INTRODUCTION}

Truck haulage is the most common means used for moving ore/waste in open-pit mining operations, but it is usually the most expensive unit operation in a truckshovel mining system. The state-of-the-art in computing technology has advanced to a point where there are several truck dispatching systems which offer the potential of improving truck-shovel productivity and subsequent savings. Introducing a dispatching system in a mine can achieve operational gains by reducing waiting times and obtain other benefits through better monitoring, optimal routing and grade control.

Efficiency of the employed truck-shovel fleet depends on the dispatching strategy in use, the complexity of the truck-shovel system and a variety of other variables. It is a common situation in mining that considerable analysis of the available strategies is undertaken before dispatching is adopted. In most cases, computer simulation is the most applicable and effective method of comparing the alternative dispatching strategies.

When designing dispatching systems, it is natural to attempt to design the best possible system relative to some performance criteria, but subject to mining and resources constraints. If the number of alternative system designs is not too large, the standard approaches for solving optimization problems are used: ranking and selection, and multiple comparisons with the best. Ranking and selection procedures yield one decision, i.e., which system design has maximum expected performance, while multiple comparisons with the best provides estimates, i.e., the difference between the expected performance of each system design and the best of the other system designs. However, this theory is not extensively used in practice. Some cite the lack of computer software for ranking and selection as the reason for its nonusage. Another reason is that traditional indifference zone selection calls for a multi-stage experimentation in the usual case of unknown variability. Since most practitioners carry out their experiments in a single stage rather than follow specific multistage designs, there has been little incentive to write computer programs for indifference zone selection (Hsu, 1984).

This paper describes an approach based on multiple comparison with the best (Hsu and Nelson, 1988) which is particularly useful when the goal is to find the system design having maximum expected performance. A refinement to the $\mathrm{MCB}$ procedure was presented by Yang and Nelson (1989) using a variance reduction technique (VRT) known as common random numbers (CRN). The objective of this study is to utilize the MCB and the MCB plus 
CRN techniques via simulation to design an optimal truck dispatching system and compare the affect of these two procedures on obtaining statistically correct conclusions about simulation output analysis. The other contribution of this paper is to extend the use of the appropriate techniques for simulation output analysis in the proper scientific fashion since, in mining simulation studies, conclusions about designing systems are usually drawn on the basis of some raw simulation results.

\section{MULTIPLE COMPARISONS WITH THE BEST}

We are comparing $\mathrm{n}$ dispatching strategies and denote the $\mathrm{n}$ systems by $\mathrm{S}_{\mathrm{i}} ; \mathrm{i}=1,2, \ldots, \mathrm{n}$. The expected performance is designated as $Q_{i} ; i=1,2, \ldots, n$. If funding the system with the best (largest) expected performance is the goal, then $Q_{i}-\max Q_{p}($ for $p \neq i)$ is inferior to the best system. For each system $S_{i}$, we consider the quantity $Q_{i}-\max Q_{p}$ (for $\mathrm{p} \neq \mathrm{i}$ ) which can be called "system i performance minus the best of the other system performances."

Since in this study the objective is finding the dispatching system with the best mean performance, then if $Q_{i}-\max Q_{p}($ for $p \neq i)>0$ for all $p$, then $S_{i}$ is the best system. Otherwise, it is not the best system. Also, if $Q$ $-\max Q_{p}($ for $p \neq i)<0$ and if $(-d)<Q_{i}-\max Q_{p}$ (for $\left.p \neq i\right)$ where $d$ is a small positive number, then system $S_{i}$ is within $d$ of the best. Thus, for multiple comparisons with the best, the relevant parameters are $Q_{i}-\max Q_{p}(p \neq i)$ for $\mathrm{i}=1,2, \ldots, \mathrm{n}$.

Hsu's (1984) method of MCB, which will be described next, provides simultaneous confidence intervals for $Q_{i}-\max Q_{p}($ for $p \neq i$ ) for all $i$. By the nature of multiple comparisons, the fewer the number of statements that must be simultaneously correct, the sharper the inference. Since the systems are stochastic and estimates are based on a finite number of samples, the quantities $Q_{i}-\max Q_{p}$ (for $p \neq i$ ) are not known precisely. Let $Y_{i j}$ be the $j$ th simulation output from the ith system design and suppose $Q_{i}=E\left[\bar{Y}_{i j}\right]$ for all $j$. MCB is applicable if the balanced one-way model (1) pertains:

$$
\begin{gathered}
Y_{i j}=Q_{i}+e_{i j}, \text { for } i=1,2,3, \\
\ldots, n ; j=1,2,3 \ldots, m
\end{gathered}
$$

where: $\mathrm{e}_{11}, \ldots, \mathrm{e}_{\mathrm{nm}}$ are independent and identically distributed normal variables with mean 0 and with unknown variance $\sigma^{2}$. Model (1) implies that $m$ replications are generated from each dispatching system, and the systems are simulated independently of each other.

Estimated measures of performance $Q_{1}, Q_{2}$, $\ldots, Q_{n}$ are calculated by the sample means:

$$
\bar{Y}_{i}=\frac{1}{m} \sum_{j=1}^{m} Y_{i j}
$$

for $\mathrm{i}=1,2 \ldots, \mathrm{n}$, and $\sigma^{2}$ is estimated by the pooled sample variance:

$$
s^{2}=\frac{1}{m(n-1)} \sum_{i=1}^{n} \sum_{j=1}^{m}\left(Y_{i j}-\bar{Y}_{i}\right)^{2}
$$

Here it should be noted that the constants $n$ and $\mathrm{m}$, and the random variables $\overline{\mathrm{Y}}_{1}, \overline{\mathrm{Y}}_{2}, \ldots, \overline{\mathrm{Y}}_{\mathrm{n}}$ and $\mathrm{s}^{2}$ are the inputs to the MCB procedure.

Now let $d_{m-1, m(n-1)}$ be the upper $\alpha$ quantile of a random variable that is the maximum of $n-1$ equally correlated multivariate-t random variables with correlation $1 / 2$ and $m(n-1)$ degrees of freedom, and let $\mathrm{x}^{+}=\max \{0, \mathrm{x}\}$ and $\mathrm{x}^{-}=\min \{0, \mathrm{x}\}$. For model (1), Hsu (1984) showed that the closed interval is:

$$
\begin{aligned}
& {\left[-\left(\bar{Y}_{i}-\max _{j \neq i} \bar{Y}_{j}-d_{m-1, m(n-1)}^{\alpha} \frac{S}{\sqrt{n}}\right)^{-},\right.} \\
& \left.\left.\bar{Y}_{i}-\max _{j \neq i} \bar{Y}_{j}+d_{m-1, m(n-1)}^{\alpha} \frac{S}{\sqrt{n}}\right)^{+}\right]
\end{aligned}
$$

for $\mathrm{i}=1,2, \ldots, \mathrm{n}$ are $(1-\alpha) 100 \%$ simultaneous confidence intervals for $Q_{i}-\max Q_{p}(p \neq i)$ for all i. A detailed proof for the presented procedure is given in Hsu and Nelson (1988).

\section{MCB WITH COMMON RANDOM NUMBERS}

When comparing alternative systems using the $\mathrm{MCB}$ technique via simulation, we may achieve a significant improvement in efficiency by introducing positive correlation across the observations from different alternative systems using the easily implemented 
variance reduction technique (VRT) of common random numbers (CRN). The objective is to use the same random numbers for each alternative to obtain a large positive correlation among their performance measures on each replication. In the previous section, CRNs were not employed and we assumed that the observations across alternative systems are independent. This procedure, MCB with CRN, employs the CRNs when sampling across all $n$ systems.

Before discussing the VRT and implementation of CRN, we emphasize some basic properties of VRTs based on the Nelson (1987) paper. Suppose we estimate $Q_{i}$ with the point estimator $Y_{i}$; then if $\left\{Y_{1}, Y_{2}, \ldots, Y_{k}\right\}$ is covariance stationary:

$$
\operatorname{Var}[\overline{\mathrm{Y}}]=\frac{\alpha^{2}}{\mathrm{k}}+\frac{2}{\mathrm{k}} \sum_{\mathrm{h}=1}^{\mathrm{k}-1}\left(1-\frac{\mathrm{h}}{\mathrm{k}}\right) \gamma_{\mathrm{h}}
$$

where $\gamma_{h}=\operatorname{Cov}\left[Y_{i}, Y_{j}\right]$ when $|i-j|=h$.

If the $Y_{j}$ are independent, as they are for independent replications, then (5) reduces to $\sigma^{2} / \mathrm{k}$.

Now, let $\left\{X_{1}, X_{2}, \ldots, X_{k}\right\}$ be a sequence of identically distributed scalar random variables. Let $Z_{j}=$ $\mathrm{Y}_{\mathrm{j}}+\mathrm{BX}_{\mathrm{j}}$, where $\mathrm{b}$ is a constant. Then:

$$
\operatorname{Var}\left[Z_{j}\right]=\sigma^{2}+b^{2} \sigma_{x}^{2} \pm 2 b \operatorname{Cov}\left[Y_{j}, X_{j}\right]
$$

where $\sigma_{x}^{2}=\operatorname{Var}\left[X_{j}\right]$. Result (5) indicates that there are three components that determine the variance of a sample mean: $\sigma^{2}, \gamma_{k}$, and $k$. Decreasing $\sigma^{2}$ and $\gamma_{k}$, or increasing $k$, reduces $\operatorname{Var}[\bar{Y}]$. Result (6) shows that the combination of $Y_{j}$ with another random variable $X_{j}$ may yield a random variable with smaller variance, provided the covariance between them is large enough and has the correct sign. Variance reduction is achieved by designing a simulation experiment to take advantage of these results.

As we can see, the goal of the CRN technique is to reduce the total number of replications needed to ensure the specified probability of correct system selection using the MCB procedure. In experimental design, it means that we use the same random numbers within pairs of replications as a means of inducing the needed positive covariance between the responses within a paired set of replications. However, using the same random number seeds for each replication within the pair is usually not sufficient to induce covariance. Therefore, we must also ensure that random numbers are synchronized, i.e., the random numbers are used at the same junction and for exactly the same purpose across all systems. One can obtain dramatic differences in the effectiveness of CRNs depending on how one performs synchronization. For some suggestions on how to obtain synchronization see Bartley, Fox and Scharge (1987).

In this simulation, experiment synchronization is handled in such a way that processing times for all sampling variables are assigned to an entity (for example, a truck) at arrival. As a result, the order in which the jobs (trucks) are processed will not change the way that the random numbers are used within the model.

\section{TRUCK HAULAGE DISPATCHING CRITERIA}

The nature of the mining system in many open-pit mines involves a fairiy complicated queuing problem. The primary servers (shovels or front-end loaders) each can serve only one truck at a time. Hence, queues form at each server. There may be multiple dump points for mineral matter; for example, ore (the most valuable mineral product), leach (of marginal, but positive value), and waste (of no value) may all be dumped in different places and multiple dumps may be available for each product. To complicate the matter, queues may form at some of the dump points. Additionally, the shovels and trucks may have different production capability.

Historically, open-pit mining operations were run with each truck assigned to a given shovel. With modern computer monitoring and control, the usual strategy is to dispatch the trucks to whichever shovel will contribute the most to the short-term production objectives. Many dispatching methods can be used, both heuristic and pseudo-optimal. Four methods are listed below as examples of the heuristic dispatching criteria:

(1) Minimizing shovel wait time (MSWT): the empty truck in this criterion is assigned to the shovel which has been waiting for a truck the longest time, or is expected to be idle next.

(2) Minimizing truck cycle time (MTCT): the goal of this strategy is to assign an available empty truck to the shovel which will provide the minimum value for completion of the expected truck cycle time to maximize either total tons or ton-miles 
per unit of time.

(3) Minimizing truck waiting time (MTWT): the objective of this criterion is to assign an empty truck to the shovel where the truck loading operation will be initiated first.

(4) Minimizing shovel saturation (MSS): the goal of this rule is to assign the trucks to the shovel at equal time intervals to keep a shovel operating without waiting for trucks. The truck is assigned to the shovel which has the lowest ratio of the current coverage against desired coverage.

\section{EVALUATION OF DISPATCHING STRATEGIES USING MCB}

A truck dispatching simulation model has been developed for the purpose of the simulation experiments. The simulation language SIMAN IV (Pegden, Shannon, and Sadowski, 1990) was used to develop the truck-shovel simulation model which can run either on mainframe workstations or PCs. SIMAN is a general-purpose SIMulation ANalysis program for modeling discrete and/or continuous systems. It is an advanced

$\mathrm{C}$-based language that allows discrete models to be built using either a process- or event-scheduling mode. The truck-shovel simulation system is composed of 4 loading shovels, 14 identical trucks and the haulage configuration shown in Figure 1. The mine simulated is an actual operation located in the southwest United States.
For MCB model (1) to be tenable, the experiment must be performed so that, for fixed criteria, $Y_{i j}(j=1$, $2, \ldots, \mathrm{m})$ are identically and independently distributed, and $Y_{i j}$ are independent for all $\mathbf{i}$ and $\mathbf{j}$. In practice, this means that different random number (RN) streams are used to generate stochastic values for the simulation of each criteria. The stochastic elements and RN streams are summarized in Table 1. The simulation time period selected was 480 minutes based on actual operating time in one shift. This value was kept constant for all the simulations runs. The systems are evaluated on the basis of total production by all trucks, $\mathrm{Q}_{i}$ (total production), as the measure of performance. Each system employs a different truck dispatching criterion. The simulation experiment using $\mathrm{MCB}$ proceeds as follows:

(1) Make $m_{0} \geq 10$ independent replications $Y_{i 1}$, $\mathrm{Y}_{\mathrm{i} 2}, \ldots, \mathrm{Y}_{\mathrm{im}_{0}}$ for each system $\mathrm{i}(\mathrm{i}=1,2, \ldots, \mathrm{n})$.

(2) Use the MCB procedure to construct simultaneous confidence intervals for system $\mathbf{i}(\mathrm{i}=1,2$, $\ldots, n)$ and check if the best system can be chosen. If yes, go to step 4.

(3) Make additional replications for the remaining systems and go to step 2 .

(4) Select the best system with the MCB CI lower bound equal to 0 .

The simulation data with statistics for our experiment are given in Table 2 and plotted in Figure 2. With a confidence level of $95 \%, \mathrm{MCB}$ subset

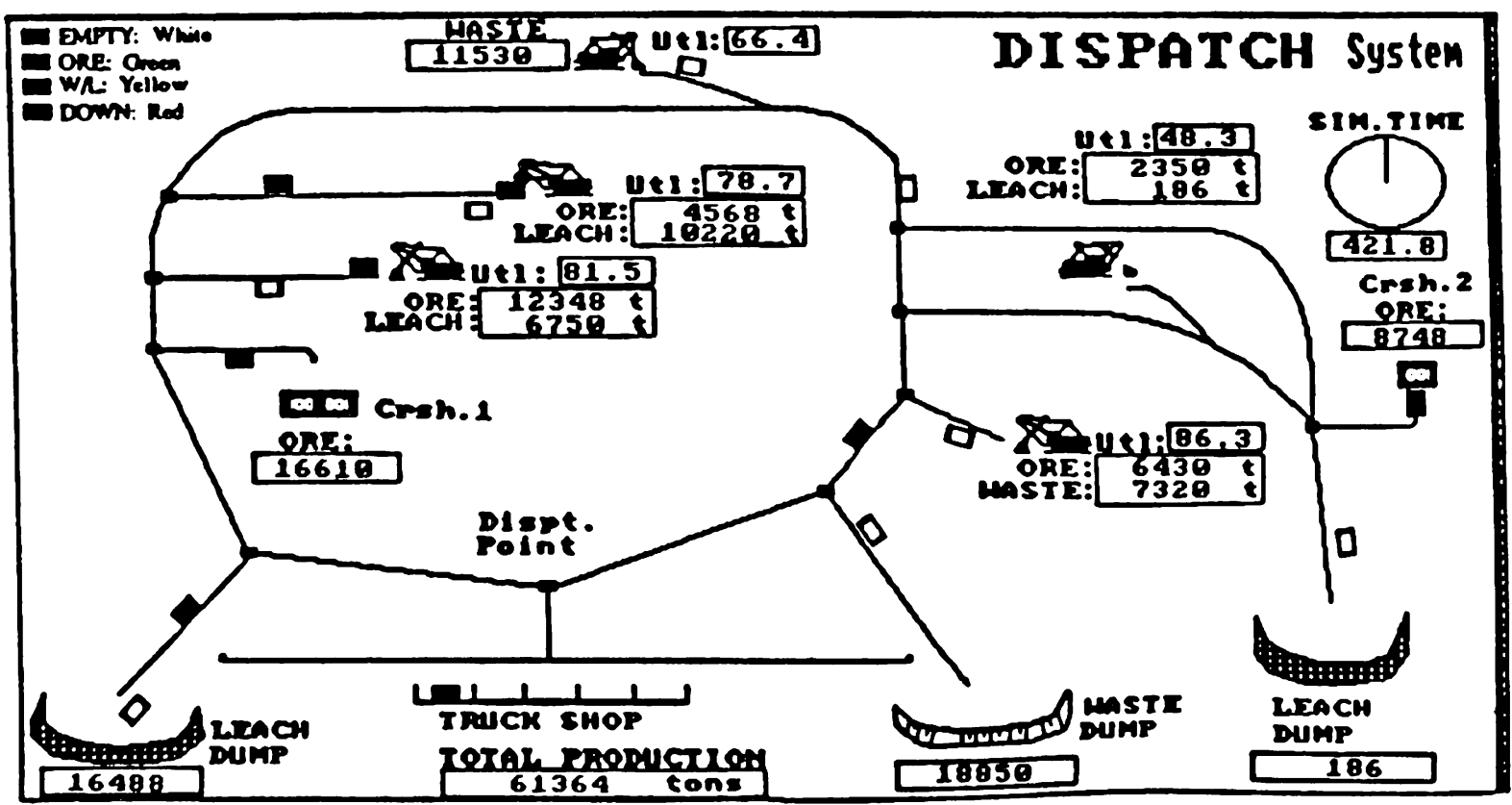

Figure 1: Layout of the Truck Haulage System 
Table 1: Stochastic Elements, RN Streams, and CRN Seeds

\begin{tabular}{|c|c|c|}
\hline Time Variable & SIMAN RN Parameters & Units \\
\hline $\begin{array}{l}\text { Loading Times: } \\
\text { 1. Shovel Type I } \\
\text { 2. Sbovel Type II } \\
\text { Spotting time: } \\
\text { Dumping time: } \\
\text { Time between shovel breakdowns: } \\
\text { Time to repair shovel: } \\
\text { Time between truck breakdowns: } \\
\text { Time to repair truck: } \\
\text { Time between crusher breakdowns: } \\
\text { Time to repair crusher: } \\
\text { EXPERMENT FULE: } \\
\text { SEEDS: 1, 12355, c: } \\
\text { 2, 13189, c: } \\
\text { 3, 15222, c: } \\
\text { 4, 11000, c: } \\
\text { 5, 13888, c: } \\
\text { 6, 14180, c: } \\
7,16272, \mathrm{c:} \\
8,17100, \mathrm{c}: \\
9,20189, \mathrm{c}: \\
10,25222, \mathrm{c:}\end{array}$ & $\begin{array}{l}\text { 120+GAMMA }(14.7,5.9,1) \\
110+\text { GAMMA }(15,3,3.1,2) \\
10+\text { LOGN }(7.8,4.6,3) \\
25+\text { LOGN }(16.2,10.8,4) \\
0.5+\text { WEIB }(17.7,0.97,5) \\
0.5+\text { WEIB }(1.6,0.43,6) \\
0.5+\text { WEIB }(36.3,0.74,9) \\
0.5+\text { WEIB }(3.2,0.51,8) \\
0.4+\text { WEIB }(6.8,0.74,9) \\
0.2+\text { WEIB }(0.97,0.63,10)\end{array}$ & $\begin{array}{l}\text { Sec } \\
\text { Sec } \\
\text { Sec } \\
\text { Sec } \\
\text { Hr. } \\
\text { Hr. } \\
\text { Hr. } \\
\text { Hr. } \\
\text { Hr. } \\
\text { Hr. }\end{array}$ \\
\hline
\end{tabular}

Table 2: Simulation Results for Ten Replications

\begin{tabular}{|c|c|c|c|c|}
\hline \multirow[t]{2}{*}{ Replication } & C $\mathrm{R}$ & I $T E$ & $R$ I $O$ & $\mathrm{~N}$ \\
\hline & MSWT & MTCT & MTWT & MSS \\
\hline 1 & 138 & 139 & 138 & 132 \\
\hline 2 & 136 & 137 & 145 & 138 \\
\hline 3 & 142 & 138 & 139 & 141 \\
\hline 4 & 138 & 131 & 140 & 139 \\
\hline 5 & 140 & 141 & 136 & 134 \\
\hline 6 & 137 & 131 & 139 & 137 \\
\hline 7 & 142 & 134 & 145 & 140 \\
\hline 8 & 135 & 137 & 146 & 136 \\
\hline 9 & 143 & 130 & 145 & 132 \\
\hline 10 & 144 & 128 & 138 & 141 \\
\hline AVERAGE: & 139.5 & 134.6 & 141.1 & 137.1 \\
\hline
\end{tabular}

\section{OUTPUT DATA FOR MCB}

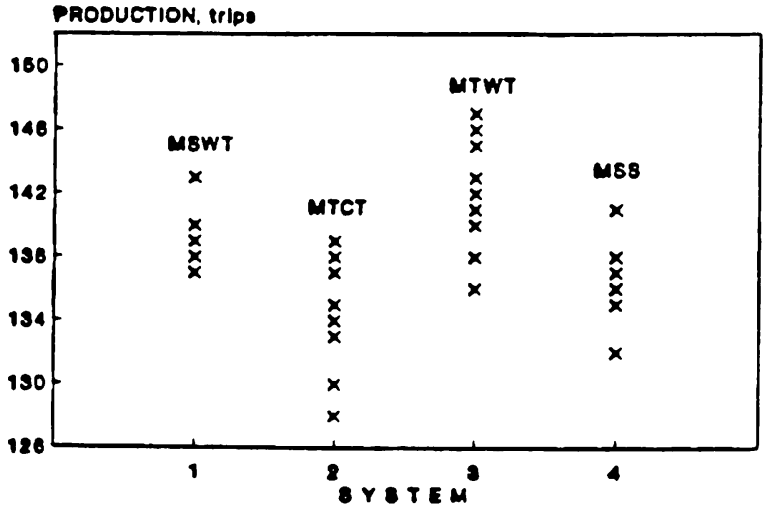

Figure 2: Simulation Responses for Four Dispatching Systems

\section{MCB CONFIDENCE INTERVALS O REPLICATIONS}

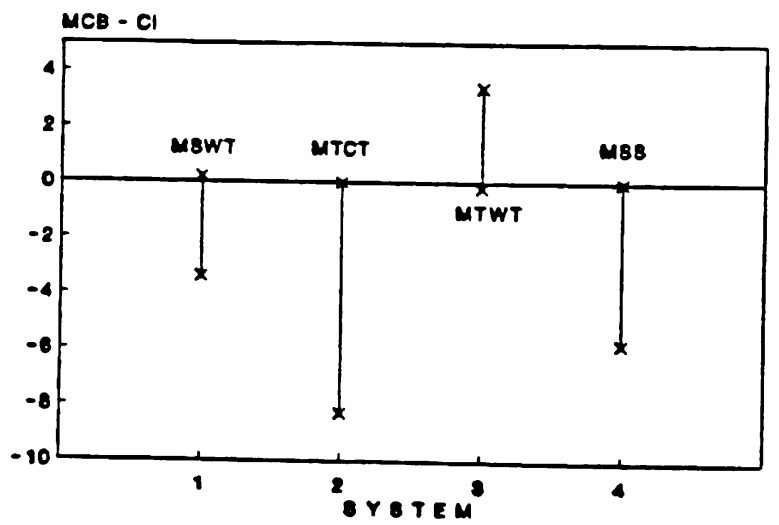

Figure 3: MCB Confidence Intervals for Four Dispatching Systems

Table 3: MCB Results for Ten Replications

\begin{tabular}{cccc}
\hline $\begin{array}{l}\text { System } \\
\text { Design }\end{array}$ & $Y_{1}$ & $Y_{1}-\max _{p=1} Y_{p}$ & $\begin{array}{c}\text { Confidence } \\
\text { Interval at } \alpha=0.05\end{array}$ \\
\hline MSWT & 139.5 & -1.6 & $(-3.4,0.2)$ \\
MTCT & 134.6 & -6.5 & $(-8.3,0.0)$ \\
MTWT & 141.1 & 1.6 & $(-0.2,3.4)$ \\
MSS & 137.1 & -4.0 & $(-5.8,0.0)$ \\
\hline
\end{tabular}

SAMPLE VARIANCE: $S^{2}-\frac{1}{m(n-1)} \sum_{i=1}^{n} \sum_{j=1}^{m}\left(Y_{i j}-\overline{Y_{1}}\right)^{2}-11.35$

DEGREES OF FREEDOM: $\mathrm{m}(\mathrm{n}-\mathrm{l})=36$ 


\section{OUTPUT DATA FOR MCB}

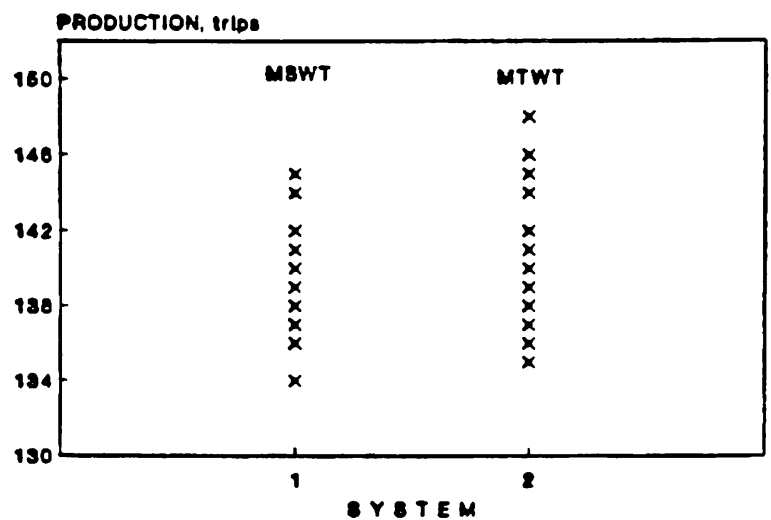

Figure 4: Simulation Responses for the MSWT and MTWT Systems

\section{MCB CONFIDENCE INTERVALS}

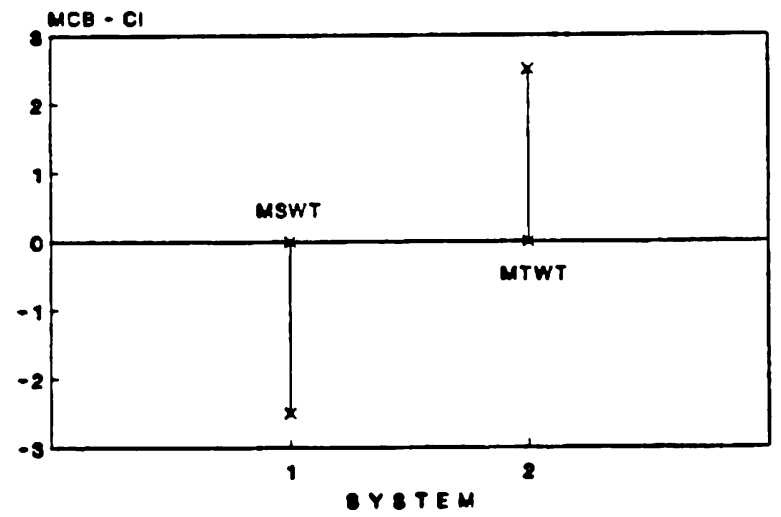

Figure 5: MCB \& CRN Confidence Intervals for the MSWT and MTWT Systems

Table 4: Simulation and MCB Results for MSWT and MTWT with 83 Replications

\begin{tabular}{c|r|c|c}
\hline $\begin{array}{c}\text { System } \\
\text { Design }\end{array}$ & $\mathrm{Y}_{\mathrm{i}}$ & $\mathrm{Y}_{\mathrm{i}}-\max _{\mathrm{pxt} 1} \mathrm{Y}_{\mathrm{p}}$ & $\begin{array}{c}\text { Confidence } \\
\text { Interval at } \alpha=0.05\end{array}$ \\
\hline MSWT & 140.8 & -1.3 & $(-2.5,0.0)$ \\
MTWT & 142.1 & 1.3 & $(0.0,2.5)$ \\
\hline
\end{tabular}

SAMPLE VARIANCE: $s^{2}=\frac{1}{m(n-1)} \sum_{j=1}^{\infty} \sum_{j=1}^{m}\left(Y_{i j}-\bar{Y}\right)^{2}-6.63$

DEGREES OF FREEDOM: $m(n-1)=328$ selection showed that criteria MSS and MTCT are not the best (see Figure 3 and Table 3) since the upper endpoint of their intervals is zero. This means that the difference between zero criteria MSS and MTCT and the other criteria with the best expected performance is less than or equal to 0 . Although criterion MTWT appears to be the best according to the measure of performance, we cannot conclude that it is best since the intervals for criteria MSWT and MTWT contain 0 , or stated differently, the random variation across the systems is too large relative to the differences $Q_{i}-\max _{p \neq i} Q_{p}$ to determine the best system.

To choose the best dispatching system, we need to perform more replications to reduce the confidence interval widths in order to select the system with the best performance. We continued with simulation replications to experimentally determine how many additional replications were needed to reach a conclusion on which system is the best. After each additional replication, the MCB confidence intervals were tested to determine if the conclusion could be achieved. The experiment was performed under the same simulation conditions for both the MSWT and the MTWT systems.

To reach a conclusion that system MTWT is superior to system MSWT, 83 replications were needed. See Figure 4 for simulation data runs and Figure 5 for MCB confidence intervals. The additional numerical and $\mathrm{MCB}$ data are given in Table 4.

\section{EVALUATION OF DISPATCHING STRATEGIES USING MCB WITH CRN}

As was mentioned earlier, the goal of CRNs is to reduce the total number of replications needed to ensure the specified probability of correct selection using the MCB procedure. To ensure that the jth replication within each of the two runs uses the same starting seed, the SEEDS element of SIMAN was employed to specify the same starting seed for the first replication within each run and for the reinitialization option "c," which denotes common random numbers. For a summary of the RN streams and $\mathrm{RN}$ seeds employed for the experiment using MCB with CRN, see Table 1 .

With the specifications in Table 1, SIMAN uses a starting seed for the next replication that is exactly 100,000 observations away from the starting seed used on the previous replication. Thus, we are 
assured that the jth replication in each of the two runs starts with the same random number, even if the number of samples generated from replication to replication differs between the two systems. It is important that the CRN technique be synchronized between replications and competing systems by the use of assigned attributes as described in section 3 . The simulation experiment proceeds as follows:

(1) Make $m_{0} \geq 10$ replications $Y_{i 1}, Y_{i 2}, \ldots, Y_{i m_{0}}$ for system $\mathrm{i}(\mathrm{i}=1,2, \ldots, \mathrm{n})$ using $\mathrm{CRN}$.

(2) Use the MCB procedure to construct simultaneous confidence intervals for system $\mathbf{i}(i=1,2, \ldots, n)$ and check if the best system can be chosen. If yes, go to step 4.

(3) Make additional replications for the remaining systems and go to step 2 .

(4) Select the best system with the MCB CI lower bound equal to 0 .

The numerical simulation responses and the $\mathrm{MCB}$ confidence intervals are summarized in Table 5. Figure 6 and Figure 7 show simulation output data and the MCB confidence intervals respectively. As can be seen, 43 replications were needed to achieve a conclusion as to which system is the best using the MCB with CRN procedure.

Table 5: Simulation and MCB Results for 43 Runs

\begin{tabular}{c|c|c|c}
\hline $\begin{array}{c}\text { System } \\
\text { Design }\end{array}$ & $\mathrm{Y}_{1}$ & $\mathrm{Y}_{\mathrm{i}}-\max _{\mathrm{p} \times 1} \mathrm{Y}_{\mathrm{p}}$ & $\begin{array}{c}\text { Confidence } \\
\text { Interval at } \alpha=0.05\end{array}$ \\
\hline MSWT & 141.3 & -1.2 & $(-2.05,0.0)$ \\
MTCT & 136.2 & -6.1 & $(-7.43,0.0)$ \\
MTWT & 142.5 & 1.2 & $(0.0,2.05)$ \\
MTCT & 138.8 & -3.7 & $(-4.85,0.0)$ \\
\hline
\end{tabular}

SAMPLE VARIANCE: $\quad S^{2}-\frac{1}{m(n-1)} \sum_{i=1}^{2} \sum_{j=1}^{\infty}\left(Y_{j}-Y_{j}\right)^{2}-4.73$

DEGREES OF FREEDOM: $m(n-1)=168$

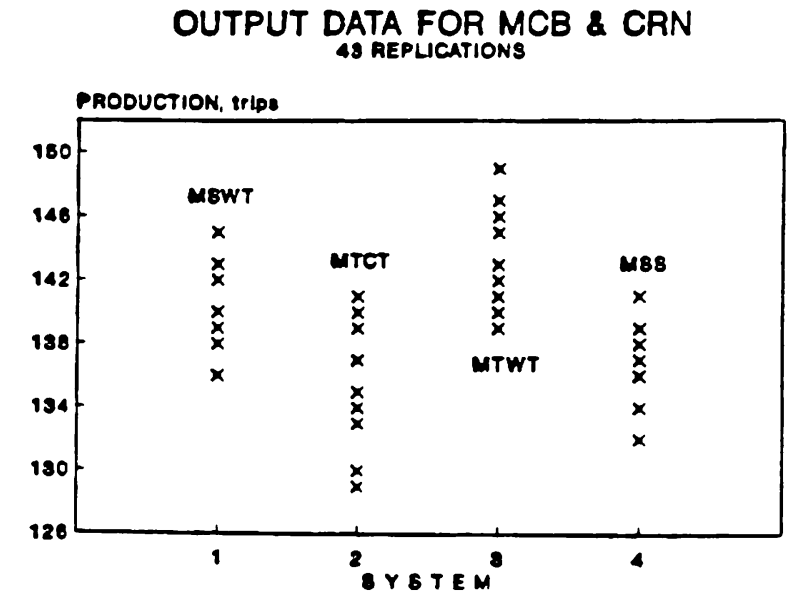

Figure 6: Simulation Responses for Four Dispatching Systems

MCB CONFIDENCE INTERVALS FOR MCB \& CRN

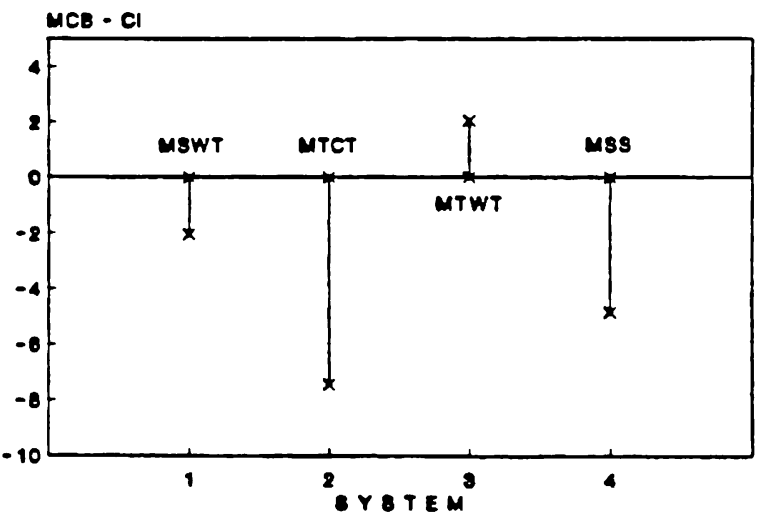

Figure 7: MCB Plus CRN Confidence Intervals for Four Dispatching Systems

Table 6: Comparison of Results

\begin{tabular}{cccc}
\hline & MCB & MCB with CRN & Rcductions \\
\hline $\begin{array}{c}\text { Number of } \\
\text { Rcplications }\end{array}$ & 83 & 43 & $48 \%$ \\
\hline MCB Cl: & $(0.0,2.5)$ & $(0.0,2.05)$ & $18 \%$ \\
\hline Variance: & 6.63 & 4.73 & $29 \%$ \\
\hline
\end{tabular}




\section{CONCLUSIONS}

The primary motivation for the analyst to use a proper output analysis procedure when using stochastic simulation is to reduce the risk in making incorrect conclusions about the alternative systems. In this study, the results clearly show the utility of the MCB with CRN procedure for analyzing a finite number of alternative systems. For comparison of results obtained by both procedures, see Table 6 .

Note that the use of common random numbers with the $\mathrm{MCB}$ procedure reduced the number of replications from 83 to 43 replications, as well as reduced variance of the response differences from 6.63 to 4.73 or $29 \%$, which yields the $18 \%$ smaller MCB confidence interval. In most situations the use of the $\mathrm{CRN}$ is effective. However, common random numbers can generate a negative covariance, which leads to less accurate results than those produced by independent runs. Although the likehood of a negative covariance is small, examples have been cited in the literature. The main advantage of the $\mathrm{MCB}$ with $\mathrm{CRN}$ procedure over the standard $\mathrm{MCB}$ procedure can be summarized as follows:

(1) It is an effective tool to reduce the number of replications needed to ensure the specified probability of correct selection over a finite number of alternative systems.

(2) It produces smaller confidence intervals and gives a better reduction of variances of the differences $\bar{Y}_{i}-\bar{Y}_{k}$ $(\mathrm{k} \neq \mathrm{i})$, rather than the individual point estimators, over all systems.

(3) It can easily be implemented. If a simulation language is used (e.g., SIMAN) the same seed elements should be used across each system design, while use of a general purpose language (e.g., C) requires saving the random number seeds at the end of $m$ replications of each system so that the simulation can be restarted with the same seeds for the following iterative step.

The use of these techniques on open-pit mine dispatching strategies shows the value of the combined MCB with CRN method. The dispatching strategies or systems are quite complex and generally can be analyzed only by simulation. However, it is common in some mines that the best dispatching system is only a few percent better in production than the least effective strategy. While a few percent increase in production is economically significant, it is difficult to achieve a statistically significant conclusion concerning the best alternative system. In this case, the MCB plus CRN method allowed a conclusion to be achieved in about one- half the number of replications as the MCB method alone. Clearly, the combined method is of significant value in such a simulation experiment.

\section{REFERENCES}

Bartley, P., B. L. Fox, and L. E. Scharge. 1987. $A$ Guide to Simulation, Second Edition. New York: Springer-Verlag.

Clark, M. C. 1990. "Use of Common Random Numbers in Comparing Alternatives," Proceedings of the 1990 Winter Simulation Conference, eds. O. Balaci, R. P. Sadowski, and R. E. Nance, $367-$ 371. IEEE: Piscataway, NJ.

Hsu, J. C. and B. L. Nelson. 1988. "Optimization Over a Finite Number of Systems Designs with One-stage Sampling and Multiple Comparisons with the Best," In: Proceedings of the 1988 Winter Simulation Conference, eds. M. Abrams, P. High, and J. Comfort, 451-457. IEEE: Piscataway, NJ.

Hsu, J. C. 1988. "Constrained Simultaneous Confidence Intervals for Multiple Comparisons With the Best," Annals of Statistics, 12:1136-1144.

Hsu, J. C. 1984. "Ranking and Selection and Multiple Comparisons with the Best," In: Design of Experiments: Ranking and Selection, eds. Thomas J. Santner and Ajit C. Tamhane, 23-33. New York: Marcel Dekker.

Kolonja, B., and J. M. Mutmansky. 1993. "Analysis of Truck Dispatching Strategies for Surface Mining Operations Using SIMAN," SME Annual Meeting, Preprint 93-177, Reno, NV.

Mutmansky, J. M., and P. P. Mwasinga. 1988. "An Analysis of SIMAN as a General-Purpose Simulation Language for Mining Systems," International Journal of Surface Mining 2(1)1-6.

Nelson, L. B. 1987. "Variance Reduction for Simulation Practitioners," In: Proceedings of the 1987 Winter Simulation Conference. eds. A. Thesen, H. Grant, W. D. Kelton, 43-51. IEEE: Piscataway, NJ.

Pegden, C. D., R. E. Shannon, and R. P. Sadowski. 1990. Introduction to Simulation Using SIMAN, New York: McGraw-Hill.

Yang, W. N. and L. B. Nelson. 1989. "Optimization with the Best," In: Proceedings of the 1989 Winter Simulation Conference, eds. E. A. MacNair, K. J. Musselman, and P. Heidelberger, 444-448. IEEE: New York. 


\section{AUTHOR BIOGRAPHIES}

Bozo Kolonja is Instructor of Mining Engineering at the University of Belgrade in Yugoslavia. He has a B.S. degree in mining engineering from the University of Belgrade and has worked in the surface mining industry in Yugoslavia for a number of years. In 1990 he came to the United States and worked toward a M.S. degree in mining engineering at the Pennsylvania State University. His research was involved with the analysis of truck dispatching systems for open-pit mines using SIMAN. He graduated in 1992 and assumed his current position.

David R. Kalasky is the Product Services Manager for Systems Modeling Corporation. Prior to joining Systems Modeling, Mr. Kalasky was Manager of Simulation for Westinghouse at their Corporate Productivity and Quality Center. Mr. Kalasky holds a B.S. degree in Mining Engineering from the University of Kentucky and an M.S. degree in Mining Engineering and Operations Research from the Pennsylvania State University. His experience includes work in engineering and the management of production and quality as well as simulation consulting. $\mathrm{He}$ is a registered Professional Engineer, an active member of IIE and SCS, CPIM and instructor within APICS, invited author and speaker for SME, and was the Business Chairman for the 1990 Winter Simulation Conference.

Jan M. Mutmansky is Professor of Mining Engineering at the Pennsylvania State University. He received his B.S., M.S. and Ph.D. degrees in mining engineering at Penn State. He has previously worked for the U.S. Bureau of Mines, Kennecott Copper Corporation, the University of Utah, and West Virginia University. $\mathrm{He}$ is a Distinguished Member of the Society for Mining, Metallurgy, and Exploration, Inc. 